\title{
Improved Collision Attack on Hash Function MD5
}

\author{
Jie Liang and Xuejia Lai \\ Department of Computer Science and Engineering \\ Shanghai Jiao Tong University \\ Shanghai 200240, China \\ Email: luckyaa@sjtu.edu.cn
}

\begin{abstract}
In this paper, we present a fast attack algorithm to find two-block collision of hash function MD5. The algorithm is based on the two-block collision differential path of MD5 that was presented by Wang et al. in EUROCRYPT 2005[6]. We found that the derived conditions for the desired differential path in [6] were not sufficient to guarantee the differential path to hold and that some conditions could be relaxed to enlarge the collision set. By using technique of small range searching and omitting the computing steps to check the characteristics in algorithm, we can speed up the attack of MD5 efficiently. Compared with the Advanced Message Modification technique [5,6], the small range searching technique can correct 4 more conditions for the first iteration differential and 3 more conditions for the second iteration differential, thus improving the probability and the complexity to find collisions. The whole attack on the MD5 can be accomplished within 5 hours using a PC with Pentium4 1.70GHZ CPU.
\end{abstract}

Key words: MD5, collision, differential attacks, fast attack algorithm.

\section{Introduction}

The hash function MD5 [2] was designed by Ronald Rivest in 1992 as a strengthened version of MD4 [1]. Though some weakness has been found by B.denBoer, A.Bosselaers [3] and H.Dobbertin [4] since its publication, MD5 is widely implemented in cryptography such as digital signature, data integrity, user authentication, key agreement, e-cash and many other cryptographic schemes and protocols. Consequently, MD5 also have been used in almost all commercial security systems and products.

In the past few years, there has been significant advances in the analysis of hash function MD5. At the rump session of Crypto'04, Wang et al. [10] presented the first collision of MD5. In EUROCRYPT 2005, Wang et al. presented a two-block collision differential path of MD5 [6] that allowed us to search collisions efficiently. The complexity of finding one collision is about $2^{41}$ MD5 operations using the attack algorithm presented in [6] (we consider the extra conditions that will be discussed in section 4). In March 2005, Klima present Multi-message modifications method to find collision of MD5 on a standard notebook PC roughly in 8 hours [7,8], the complexity is 
about $2^{36}$ MD5 operations (we consider the extra conditions that will be discussed in section 4).

In this paper, we show that the conditions in Table 4 and 6 of [6] are not sufficient to ensure the occurrence of the collision path (which was also found in [12] with a different approach) and specify a set of truly sufficient conditions by adding some extra conditions. Additionally, We relax some conditions in Table 4 and 6 of [6] to enlarge the collision set. Finally we propose small range searching technique to correct more conditions in round 2 but keep all the conditions in round 1 hold. By using the small range searching technique and omitting the steps of checking characteristics in algorithm $[6,7,8]$, we can reduce the searching complexity to about $2^{34}$ MD5 operations for the first block and about $2^{28} \mathrm{MD} 5$ operations for the second block.

\section{MD5 Algorithm}

The MD5 Message-Digest Algorithm [2] is composed of integer modular addition, four auxiliary Boolean functions and left shift rotation. The processing of MD5 involves 64 steps, and can be described as following:

The chaining variables are initialized as:

$a_{0}=0 \times 67452301 ; d_{0}=0 \times 10325476 ; c_{0}=0 \times 98$ badcfe; $b_{0}=0 x e f c d a b 89 ;$

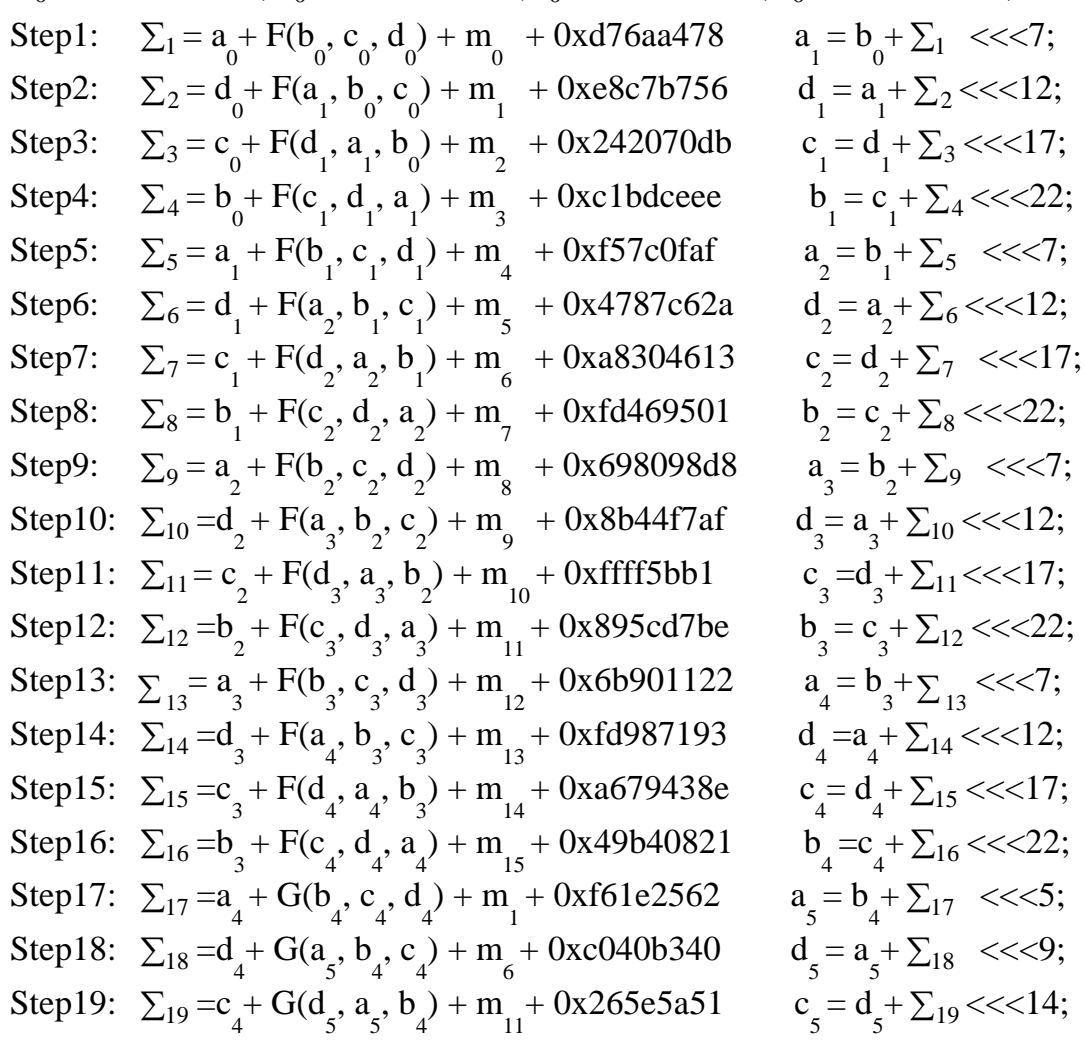


Step20: $\quad \sum_{20}=b_{4}+G\left(c_{5}, d_{5}, a_{5}\right)+m_{0}+0 x e 9 b 6 c 7 a a \quad b_{5}=c_{5}+\sum_{20} \ll<<20$;

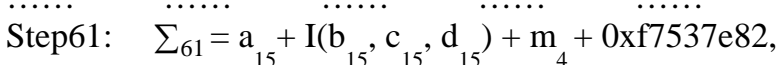
$\mathrm{a}_{16}=\mathrm{b}_{15}+\sum_{61}<<<6, \quad \mathrm{aa}_{0}=\mathrm{a}_{16}+\mathrm{a}_{0}$;

Step62: $\quad \sum_{62}=\mathrm{d}_{15}+\mathrm{I}\left(\mathrm{a}_{16}, \mathrm{~b}_{15}, \mathrm{c}_{15}\right)+\mathrm{m}_{11}+$ 0xbd3af235, $\mathrm{d}_{16}=\mathrm{a}_{16}+\sum_{62}<<<10, \quad \mathrm{dd}_{0}=\mathrm{d}_{16}+\mathrm{d}_{0}$;

Step63: $\quad \sum_{63}=\mathrm{c}_{15}+\mathrm{I}\left(\mathrm{d}_{16}, \mathrm{a}_{16}, \mathrm{~b}_{15}\right)+\mathrm{m}_{2}+0 \mathrm{x} 2 \mathrm{ad} 7 \mathrm{~d} 2 \mathrm{bb}$, $\mathrm{c}_{16}=\mathrm{d}_{16}+\sum_{63}<<<15, \quad \mathrm{cc}_{0}=\mathrm{c}_{16}+\mathrm{c}_{0}$;

Step64: $\quad \sum_{64}=\mathrm{b}_{15}+\mathrm{I}\left(\mathrm{c}_{16}, \mathrm{~d}_{16}, \mathrm{a}_{16}\right)+\mathrm{m}_{9}+0 x \operatorname{0x} 86 \mathrm{~d} 391$, $\mathrm{b}_{16}=\mathrm{c}_{16}+\sum_{64}<<<21, \quad \mathrm{bb}_{0}=\mathrm{b}_{16}+\mathrm{b}_{0}$;

Where $<<<\mathrm{K}$ is cyclically left-shift by $\mathrm{K}$ bit positions.

Let $a a_{0}, b b_{0}, c c_{0}$ and $d d_{0}$ be the output of compressing one 512-bit message block. If there are more than one message block for compression, repeat the above 64 steps with the next 512-bit message block and ( $a a_{0}, b b_{0}, c c_{0}, d d_{0}$ ) as inputs.

The four auxiliary Boolean functions used for MD5 are the following:

$\mathrm{F}(\mathrm{x}, \mathrm{y}, \mathrm{z})=(\mathrm{x} \wedge \mathrm{y}) \vee(\neg \mathrm{x} \wedge \mathrm{z})$

$\mathrm{G}(\mathrm{x}, \mathrm{y}, \mathrm{z})=(\mathrm{x} \wedge \mathrm{z}) \vee(\mathrm{y} \wedge \neg \mathrm{z})$

$\mathrm{H}(\mathrm{x}, \mathrm{y}, \mathrm{z})=\mathrm{x} \oplus \mathrm{y} \oplus \mathrm{z}$

$\mathrm{I}(\mathrm{x}, \mathrm{y}, \mathrm{z})=\mathrm{y} \oplus(\mathrm{x} \wedge \neg \mathrm{z})$

where $\mathrm{x}, \mathrm{y}, \mathrm{z}$ are 32-bit words.

In the above iterating process, we omit the padding method because it has no influence on the attack.

\section{Collision Differentials for MD5}

The collision differentials for MD5 with two iterations that Wang et al. presented in EUROCRYPT 2005 is as follows:

$$
\Delta H_{0}=0 \stackrel{\left(M_{0}, M_{0}^{\prime}\right)}{\longrightarrow} \Delta H_{1} \stackrel{\left(M_{1}, M_{1}^{\prime}\right)}{\longrightarrow} \Delta H_{2}=0
$$

Such that

$$
\begin{aligned}
& \Delta M_{0}=M_{0}^{\prime}-M_{0}=\left(0,0,0,0, * 2^{31}, 0,0,0,0,0,0,2^{15}, 0,0, * 2^{31}, 0\right) \\
& \Delta M_{1}=M_{1}^{\prime}-M_{1}=\left(0,0,0,0, * 2^{31}, 0,0,0,0,0,0,-2^{15}, 0,0, * 2^{31}, 0\right) \\
& \Delta H_{1}=\left(* 2^{31}, * 2^{31}+2^{25}, * 2^{31}+2^{25}, * 2^{31}+2^{25}\right) .
\end{aligned}
$$

Where $* 2^{31}$ means it can be $-2^{31}$ or $+2^{31}$, which is limited to $+2^{31}$ in [6]. We found that it can be relaxed to $-2^{31}$ or $+2^{31}$ but the collision differentials still hold. $M_{0}, M_{0}^{\prime}, M_{1}$ and $M_{1}^{\prime}$ each is one 512-bit message block. Non-zero entries of $\Delta M_{0}$ and $\Delta M_{1}$ are located at positions 5,12 and 15. $\Delta H_{1}=(\Delta \mathrm{a}, \Delta \mathrm{b}, \Delta \mathrm{c}, \Delta \mathrm{d})$ is the difference of the four chaining values (a, d, c, b) after the first iteration. 


\section{Sufficient Conditions for the Collision Path to Hold}

In order to construct a fast attack algorithm without the need to test whether the characteristics really hold in every step, we first derive a set of truly sufficient conditions that guarantee the collision differential path described in Table 3 and 5 of [6] to hold. In this section, we show that it needs to add some extra conditions into Table 4 and 6 of [6] to keep the path attained. More detailed explanation has been discussed in [12], they also discover the lack of conditions independently.

For example, in the $5^{\text {th }}$ step computation of the first iteration: Step5: $\mathrm{a}_{2}=\mathrm{b}_{1}+\left[\mathrm{a}_{1}+\mathrm{F}\left(\mathrm{b}_{1}, \mathrm{c}_{1}, \mathrm{~d}_{1}\right)+\mathrm{m}_{4}+0 x \mathrm{xf57} \mathrm{c}\right.$ faf $]<<<7$, Let $\quad \Sigma_{5}=\mathrm{a}_{1}+\mathrm{F}\left(\mathrm{b}_{1}, \mathrm{c}_{1}, \mathrm{~d}_{1}\right)+\mathrm{m}_{4}+0 \mathrm{xf57c0faf}$.

Then, the output difference in the $5^{\text {th }}$ step caused by $\Delta m_{4}=* 2^{31}$ should depend on the value of bit 32 in $\sum_{5}$ : if the bit 32 in $\sum_{5}$ is zero, then the output difference in the $5^{\text {th }}$ step is $2^{6}$; if the bit 32 in $\sum_{5}$ is one, then the output difference in the $5^{\text {th }}$ step is $-2^{6}$. Thus, we need to add the necessary condition $\sum_{5,32}=1$ to keep the output difference $-2^{6}$ in Table 3 of [6]. In order to use basic modification technique, we add conditions $b_{1,5}=1, b_{1,6}=1$ and $a_{2,5}=0$ (these conditions are not necessary) instead of condition $\sum_{5,32}=1$ to the set of sufficient conditions. We show the $5^{\text {th }}$ step computation of the first iteration in Table 1 . According to binary addition properties, for $\mathrm{Z}=\mathrm{X}+\mathrm{Y}$, we have:

(1) If bit $\mathrm{n}$ in $\mathrm{X}$ is unknown, bit $\mathrm{n}$ in $\mathrm{Y}$ is 1 and bit $\mathrm{n}$ in $\mathrm{Z}$ is 0 , then $\mathrm{X}+\mathrm{Y}$ will have carry to bit $n+1$.

(2) If bit $n$ in $X$ is unknown, bit $n$ in $Y$ is 0 and bit $n$ in $Z$ is 1 , then $X+Y$ will have no carry to bit $n+1$.

So we can ensure condition $\sum_{5,32}=1$ occur if conditions $\mathrm{b}_{1,5}=1, \mathrm{~b}_{1,6}=1$ and $\mathrm{a}_{2,5}=0$ hold ( see in Table 1 ).

Table 1 . Compute the $5^{\text {th }}$ Step of the First Iteration

\begin{tabular}{|l|c|llllllll|}
\hline \multicolumn{2}{|l|}{ bit NO. } & 1 & 5 & 9 & 11 & 17 & 21 & 25 & 29 \\
\hline \multirow{3}{*}{+} & $\sum_{5}<<<7$ & ???? & $? 11$ ? & ???? & ???? & ???? & ???? & ???? & ???? \\
\cline { 2 - 9 } & $\mathrm{b}_{1}$ & ???? & $110 ?$ & ???1 & ???? & ???1 & ???0 & ???? & ???1 \\
\hline$=$ & $\mathrm{a}_{2}$ & $1 ? 1 ?$ & 0100 & 0000 & 0000 & 0000 & 0010 & ?0?1 & ???1 \\
\hline
\end{tabular}

From the example, we see that it is necessary to consider the left shift rotation operation when we derive sufficient conditions for keeping the collision path. Extra conditions for other steps are derived using the same method.

During our research, we found that some conditions in Table 4 and 6 of [6] could be relaxed to enlarge the collision set. We show them as follows:

(1) Conditions in bits $\mathrm{c}_{4,32}, \mathrm{~b}_{4,32}, \mathrm{a}_{5,32}, \mathrm{~d}_{5,32}, \mathrm{c}_{5,32}, \mathrm{~b}_{5,32}, \mathrm{a}_{6,32}$ and $\mathrm{d}_{6,32}$ are not necessary to be zeros, they just need to be equal to each other for the first iteration differential and the second iteration differential. 
(2) Conditions $\mathrm{a}_{1,32}=\mathrm{d}_{1,32}=\mathrm{c}_{1,32}=\mathrm{b}_{1,32}=1, \mathrm{a}_{2,32}=\mathrm{d}_{2,32}=0, \mathrm{c}_{2,32}=\mathrm{b}_{2,32}=\mathrm{a}_{3,32}=\mathrm{d}_{3,32}=$ $\mathrm{c}_{3,32}=\mathrm{b}_{3,32}=1, \mathrm{a}_{4,32}=\mathrm{d}_{4,32}=0$ can be relaxed to $\mathrm{bb}_{0,32}=\mathrm{a}_{1,32}+1=\mathrm{d}_{1,32}+1=\mathrm{c}_{1,32}+1=$ $\mathrm{b}_{1,32}+1=\mathrm{a}_{2,32}=\mathrm{d}_{2,32}=\mathrm{c}_{2,32}+1=\mathrm{b}_{2,32}+1=\mathrm{a}_{3,32}+1=\mathrm{d}_{3,32}+1=\mathrm{c}_{3,32}+1=\mathrm{b}_{3,32}+1=\mathrm{a}_{4,32}=\mathrm{d}_{4,32}$ for the second iteration differential.

The conditions' relaxations do not have any influence on the differential characteristic in Table 3 and 5 of [6], which is easily verified by using the deriving method described in [6]. After we relax these conditions, the collision set should become at least 8 times larger than before.

Finally, we give out a set of sufficient conditions in Table 4 and 5 (in appendices) that guarantee the desired differential path to occur. The extra conditions in Table 4 and 5 are just one of the possible extra conditions sets derived from $\sum_{i}$, we choose them out as they are optimal. Compare with the Table 4 of [6], besides the relaxed conditions and the extra conditions derived from $\sum_{i}$, we also add conditions $d_{16,26}=0$, $c_{16,26}=0$, correct condition $c_{16,32}=a_{16,32}$ and delete condition $a_{16,27}=0$ in Table 4. The same to extra condition $b_{15,26}=0$ in Table 5. By using the deriving method described in [6], we confirm that these 5 conditions are lacked conditions or incorrect conditions in [6] (see counterexamples in appendices). In fact, we can derive other set of truly sufficient conditions, but the set that we show in Table 4 and 5 is the best in the sense that it contains the least number of conditions for keeping the collision path.

We note that the extra conditions $\mathrm{a}_{2,27}=0, \mathrm{a}_{2,29}=0, \mathrm{a}_{2,30}=0$ and $\mathrm{a}_{2,31}=0$, which are derived from $\sum_{7}$ of the first iteration, are not only sufficient but also necessary conditions for holding the collision path. We present a counterexample $M_{0}$ with standard IV that satisfies all the conditions in Table 4 except for conditions $a_{2,27}=1, a_{2,29}=1, a_{2,30}$ $=1$ and $\mathrm{a}_{2,31}=1$ :

$$
\begin{aligned}
& \mathrm{m}_{0}=0 \text { xe3b50fa3; } \quad \mathrm{m}_{1}=0 \mathrm{x} 4 \mathrm{be} 14 \mathrm{e} 05 ; \quad \mathrm{m}_{2}=0 \mathrm{x} 16 \mathrm{a} 10 \mathrm{a} 8 \mathrm{e} ; \quad \mathrm{m}_{3}=0 \mathrm{xf70e2ebe} \\
& \mathrm{m}_{4}=0 x 5 f a 664 \mathrm{~b} 8 ; \quad \mathrm{m}_{5}=0 x \text { e60b9ef3; } \quad \mathrm{m}_{6}=0 x-4594 \mathrm{~b} 46 ; \quad \mathrm{m}_{7}=0 \mathrm{x} 49813 \mathrm{c} 40 ; \\
& \mathrm{m}_{8}^{4}=0 \mathrm{x} 1 \mathrm{e} 332 \mathrm{~d} 55 ; \quad \mathrm{m}_{9}^{5}=0 \mathrm{x} 2 \mathrm{ff} 43 \mathrm{c} 05 ; \quad \mathrm{m}_{10}^{6}=0 \mathrm{x} 8482 \mathrm{ea} 2 \mathrm{f} ; \quad \mathrm{m}_{11}^{7}=0 \times 13823723 \text {; } \\
& \mathrm{m}_{12}=0 \mathrm{x} 31 \mathrm{c} 034 \mathrm{e} 3 ; \quad \mathrm{m}_{13}=0 \mathrm{x} 234 \mathrm{c} 14 \mathrm{e} 1 ; \quad \mathrm{m}_{14}=0 \mathrm{x} 14237194 ; \quad \mathrm{m}_{15}=0 \times 34234335 \text {. }
\end{aligned}
$$

According to Section 3, $M_{1}$ can easy to get from $M_{0}$ but they are not collision pairs for the first block at all.

We find that Jun Yajima and Takeshi Shimoyama also discover the lack of conditions in [6]. They try to present a set of sufficient conditions in [13]. By comparing, we found that the sufficient condition set they showed still lacked of conditions. Here we show out a counterexample with standard IV that satisfies all the conditions for First Message Block listed in [13] as follow:

$$
\begin{aligned}
& \mathrm{m}_{0}=0 \mathrm{x} 72 \mathrm{bcc} 7 \mathrm{~d} 2 ; \quad \mathrm{m}_{1}=0 \times 87 \mathrm{fe} 0 \mathrm{ffc} ; \quad \mathrm{m}_{2}=0 \mathrm{xc7ee} 72 \mathrm{f} 1 ; \quad \mathrm{m}_{3}=0 \times 5 \mathrm{c} 92 \mathrm{~b} 535 ; \\
& \mathrm{m}_{4}=0 x \mathrm{xb} 3 \mathrm{fbb} 6 \mathrm{~d} 4 ; \quad \mathrm{m}_{5}=0 \times \mathrm{xc} 03 \mathrm{f} 68 \mathrm{c} 8 ; \quad \mathrm{m}_{6}=0 \times 95879481 ; \quad \mathrm{m}_{7}=0 \mathrm{xf} 1 \mathrm{f} 48 \mathrm{bd} 6 ; \\
& \mathrm{m}_{8}^{4}=0 \mathrm{x} 633 \mathrm{ed} 41 ; \quad \mathrm{m}_{9}^{5}=0 \mathrm{x} 3 \mathrm{~d} 3 \mathrm{f} 800 ; \quad \mathrm{m}_{10}^{6}=0 \mathrm{x} 7 \mathrm{f} 80 \mathrm{f} 83 \mathrm{~b} ; \quad \mathrm{m}_{11}^{7}=0 \mathrm{x} 93410102 ; \\
& \mathrm{m}_{12}^{8}=0 \mathrm{x} 90 \mathrm{e} 148 \mathrm{c} 1 ; \quad \mathrm{m}_{13}=0 \mathrm{x} 129 \mathrm{cff} 6 ; \quad \mathrm{m}_{14}=0 \mathrm{xfffc} 2018 ; \quad \mathrm{m}_{15}=0 \mathrm{x} 809 \mathrm{c} 01 \mathrm{c} 1 \text {. }
\end{aligned}
$$


Through verification, we found that $\mathrm{b}_{1,5}=1, \mathrm{~b}_{1,6}=0$ and $\mathrm{a}_{2,5}=0$. These three conditions ensure $\sum_{5,32}=0$ occur to break the collision path.

\section{Construct a Fast Attack Algorithm}

In this section, we propose small range searching technique to obtain a faster attack algorithm. The basic idea of this technique is that for $N=U+[L+F(X, Y, Z)+M$ + Constant $]<<<$, we can change the value of bit $\mathrm{n}$ in $\mathrm{N}$ by searching bit $\mathrm{n}$ in $\mathrm{U}$ and bit n-k in L, X, Y, Z, M; We can also search the bits lower than $n$ in $U$ and bits lower than $n-k$ in $L, X, Y, Z, M$ to change the value of bit $n$ in $N$ by carry.

Through experiment, we found that the basic message modification technique described in [6] was not always success because of the Carry or Borrow in bit 32. So our basic message modification technique shown below different from the one presented in [6], and we can make the modification always succeed.

\subsection{Fast Attack Algorithm for First Block}

(a) Select random 32-bit value for $\mathrm{m}_{0}, \mathrm{~m}_{1}, \mathrm{~m}_{2} \ldots \mathrm{m}_{15}$.

(b) Compute step 1 and step 2 of MD5 algorithm, modify $m_{2} \ldots m_{13}, m_{14}$ and $m_{15}$ by basic message modification technique. For example, $m_{5}$ should be modified to ensure the conditions of $\mathrm{d}_{2}$ in Table 4 hold (see in Table 2):

Step6: $\mathrm{d}_{2}=\mathrm{a}_{2}+\left[\mathrm{d}_{1}+\mathrm{F}\left(\mathrm{a}_{2}, \mathrm{~b}_{1}, \mathrm{c}_{1}\right)+\mathrm{m}_{5}+0 \mathrm{x} 4787 \mathrm{c} 62 \mathrm{a}\right]<<<12$;

Table 2. Conditions of $d$ for the First Iteration Differential

$\mathrm{d}_{2,1}=1, \mathrm{~d}_{2,2}=\mathrm{a}_{2,2}, \mathrm{~d}_{2,3}=0, \mathrm{~d}_{2,4}=\mathrm{a}_{2,4}, \mathrm{~d}_{2,5}=\mathrm{a}_{2,5}, \mathrm{~d}_{2,6}=0, \mathrm{~d}_{2,7}=1, \mathrm{~d}_{2,8}=0, \mathrm{~d}_{2,9}=0$,
$\mathrm{d}_{2,10}=0, \mathrm{~d}_{2,11}=1, \mathrm{~d}_{2,12}=1, \mathrm{~d}_{2,13}=1, \mathrm{~d}_{2,14}=1, \mathrm{~d}_{2,15}=0, \mathrm{~d}_{2,16}=1, \mathrm{~d}_{2,17}=1, \mathrm{~d}_{2,18}=1$
$\mathrm{~d}_{2,19}=1, \mathrm{~d}_{2,20}=1, \mathrm{~d}_{2,21}=1, \mathrm{~d}_{2,22}=1, \mathrm{~d}_{2,23}=1, \mathrm{~d}_{2,24}=0, \mathrm{~d}_{2,25}=\mathrm{a}_{2,25}, \mathrm{~d}_{2,26}=1$,
$\mathrm{d}_{2,27}=\mathrm{a}_{2,27}, \mathrm{~d}_{2,28}=0, \mathrm{~d}_{2,29}=\mathrm{a}_{2,29}, \mathrm{~d}_{2,30}=\mathrm{a}_{2,30}, \mathrm{~d}_{2,31}=\mathrm{a}_{2,31}, \mathrm{~d}_{2,32}=0$

Basic Modification:

$\mathrm{d}_{2}=\left\{\left(\mathrm{d}_{2}\right)^{\wedge}\left[\left(\mathrm{d}_{2}\right) \&(\right.\right.$ 0xfd8043be $\left.)\right] \wedge\left[\left(\mathrm{a}_{2}\right) \&(\right.$ 0x7500001a $\left.\left.)\right]\right\} \mid($ 0x027fbc41 )

$\mathrm{m}_{5}=\left[\left(\mathrm{d}_{2}-\mathrm{a}_{2}\right)>>>12\right]-\mathrm{d}_{1}-\mathrm{F}\left(\mathrm{a}_{2}, \mathrm{~b}_{1}, \mathrm{c}_{1}\right)-0 \mathrm{x} 4787 \mathrm{c} 62 \mathrm{a}$.

In order to use small range searching technique in the next step, we add three extra conditions $\mathrm{c}_{4,9}=0, \mathrm{c}_{4,21}=0$ and $\mathrm{c}_{4,23}=0$ in $\mathrm{c}_{4}$ when Modify $\mathrm{m}_{14}$.

(c) Randomly select 32-bit value for $\mathrm{a}_{5}$ but make the conditions $\mathrm{a}_{5,4}=\mathrm{b}_{4,4}, \mathrm{a}_{5,16}=\mathrm{b}_{4,16}$, $\mathrm{a}_{5,18}=0, \mathrm{a}_{5,31}=1$ and $\mathrm{a}_{5,32}=\mathrm{b}_{4,32}$ hold, then compute the $18^{\text {th }}$ step:

$\Sigma_{18}=d_{4}+G\left(a_{5}, b_{4}, c_{4}\right)+m_{6}+0 x c 040 b 340 \quad d_{5}=a_{5}+\sum_{18}<<<9$. 
If conditions $\mathrm{d}_{5,18}=1, \mathrm{~d}_{5,30}=\mathrm{a}_{5,30}$ and $\mathrm{d}_{5,32}=\mathrm{a}_{5,32}$ are not all hold, we use small range searching technique to correct them. According to the $18^{\text {th }}$ step computation and extra conditions $\mathrm{C}_{4,9}=0, \mathrm{c}_{4,21}=0$ and $\mathrm{c}_{4,23}=0$ in $\mathrm{c}_{4}$, we notice that by searching bits $b_{4,9}, b_{4,21}, b_{4,23}$ in $b_{4}$, we can change the value of bits $d_{5,18}, d_{5,30}, d_{5,32}$ in $d_{5}$ to make the conditions $\mathrm{d}_{5,18}=1, \mathrm{~d}_{5,30}=\mathrm{a}_{5,30}$ and $\mathrm{d}_{5,32}=\mathrm{a}_{5,32}$ hold, then we need to update the value of $m_{15}$ :

$\mathrm{m}_{15}=\left[\left(\mathrm{b}_{4}-\mathrm{c}_{4}\right)>>>22\right]-\mathrm{b}_{3}-\mathrm{F}\left(\mathrm{c}_{4}, \mathrm{~d}_{4}, \mathrm{a}_{4}\right)-0 \mathrm{x} 49 \mathrm{~b} 40821$.

(d) Compute the $19^{\text {th }}$ step:

$$
\Sigma_{19}=c_{4}+G\left(d_{5}, a_{5}, b_{4}\right)+m_{11}+0 x 265 e 5 a 51 \quad c_{5}=d_{5}+\sum_{19}<<<14 .
$$

If conditions $\sum_{19,4} \sim \sum_{19,8}$ not all ones, $c_{5,18}=0$ and $c_{5,32}=d_{5,32}$ are not all fulfilled, we use small range searching technique to correct them. By searching bits $b_{3,4}, b_{3,5}$, $b_{3,6}, b_{3,7}, b_{3,21}, b_{3,22}, b_{3,23}, b_{3,24}$ in $b_{3}$ and update the value of $m_{11}\left(m_{11}=\left[\left(b_{3}-c_{3}\right)\right.\right.$ $\left.>>22]-b_{2}-F\left(c_{3}, d_{3}, a_{3}\right)-0 x 895 c d 7 b e\right)$, we can affect the value of $c_{5}$ to make the conditions $\sum_{19,4} \sim \sum_{19,8}$ not all ones, $c_{5,18}=0$ and $c_{5,32}=d_{5,32}$ hold. Finally, we update the value of $\mathrm{m}_{12}, \mathrm{~m}_{13}, \mathrm{~m}_{14}, \mathrm{~m}_{15}$ :

$\mathrm{m}_{12}=\left[\left(\mathrm{a}_{4}-\mathrm{b}_{3}\right)>>>7\right]-\mathrm{a}_{3}-\mathrm{F}\left(\mathrm{b}_{3}, \mathrm{c}_{3}, \mathrm{~d}_{3}\right)-0 \times 6 \mathrm{~b} 901122$,

$\mathrm{m}_{13}=\left[\left(\mathrm{d}_{4}-\mathrm{a}_{4}\right)>>>12\right]-\mathrm{d}_{3}-\mathrm{F}\left(\mathrm{a}_{4}, \mathrm{~b}_{3}, \mathrm{c}_{3}\right)-0 \mathrm{xfd} 987193$,

$\mathrm{m}_{14}=\left[\left(\mathrm{c}_{4}-\mathrm{d}_{4}\right)>>>17\right]-\mathrm{c}_{3}-\mathrm{F}\left(\mathrm{d}_{4}, \mathrm{a}_{4}, \mathrm{~b}_{3}\right)-0 \times \mathrm{xa679438} \mathrm{e}$,

$\mathrm{m}_{15}=\left[\left(\mathrm{b}_{4}-\mathrm{c}_{4}\right)>>>22\right]-\mathrm{b}_{3}-\mathrm{F}\left(\mathrm{c}_{4}, \mathrm{~d}_{4}, \mathrm{a}_{4}\right)-0 \mathrm{x} 49 \mathrm{~b} 40821$.

(e) Randomly select 32-bit value for $\mathrm{b}_{5}$ but make the conditions $\sum_{20,30} \sim \sum_{20,32}$ not all zeros and $b_{5,32}=c_{5,32}$ hold, then update the value of $m_{1}, m_{0}, a_{1}, d_{1}, m_{2}, m_{3}, m_{4}$ and $m_{5}$ : $\mathrm{m}_{1}=\left[\left(\mathrm{a}_{5}-\mathrm{b}_{4}\right)>>>5\right]-\mathrm{a}_{4}-\mathrm{G}\left(\mathrm{b}_{4}, \mathrm{c}_{4}, \mathrm{~d}_{4}\right)-0 \mathrm{xf6} 61 \mathrm{e} 2562$,

$\mathrm{m}_{0}=\left[\left(\mathrm{b}_{5}-\mathrm{c}_{5}\right)>>>20\right]-\mathrm{b}_{4}-\mathrm{G}\left(\mathrm{c}_{5}, \mathrm{~d}_{5}, \mathrm{a}_{5}\right)-0 \mathrm{xe} 9 \mathrm{~b} 6 \mathrm{c} 7 \mathrm{aa}$,

$\mathrm{a}_{1}=\mathrm{b}_{0}+\left[\mathrm{a}_{0}+\mathrm{F}\left(\mathrm{b}_{0}, \mathrm{c}_{0}, \mathrm{~d}_{0}\right)+\mathrm{m}_{0}+0 \mathrm{xd} 76 \mathrm{aa}_{4} 48\right]<<<7$,

$\mathrm{d}_{1}=\mathrm{a}_{1}+\left[\mathrm{d}_{0}+\mathrm{F}\left(\mathrm{a}_{1}, \mathrm{~b}_{0}, \mathrm{c}_{0}\right)+\mathrm{m}_{1}+0 \mathrm{xe} 8 \mathrm{c} 7 \mathrm{~b} 756\right]<<<12$,

$\mathrm{m}_{2}=\left[\left(\mathrm{c}_{1}-\mathrm{d}_{1}\right)>>>17\right]-\mathrm{c}_{0}-\mathrm{F}\left(\mathrm{d}_{1}, \mathrm{a}_{1}, \mathrm{~b}_{0}\right)-0 \times 242070 \mathrm{db}$,

$\mathrm{m}_{3}=\left[\left(\mathrm{b}_{1}-\mathrm{c}_{1}\right)>>>22\right]-\mathrm{b}_{0}-\mathrm{F}\left(\mathrm{c}_{1}, \mathrm{~d}_{1}, \mathrm{a}_{1}\right)-0 \mathrm{xc} 1 \mathrm{bdceee}$,

$\mathrm{m}_{4}=\left[\left(\mathrm{a}_{2}-\mathrm{b}_{1}\right)>>>7\right]-\mathrm{a}_{1}-\mathrm{F}\left(\mathrm{b}_{1}, \mathrm{c}_{1}, \mathrm{~d}_{1}\right)-0 x f 57 \mathrm{c} 0 \mathrm{faf}$,

$\mathrm{m}_{5}=\left[\left(\mathrm{d}_{2}-\mathrm{a}_{2}\right)>>>12\right]-\mathrm{d}_{1}-\mathrm{F}\left(\mathrm{a}_{2}, \mathrm{~b}_{1}, \mathrm{c}_{1}\right)-0 \times 4787 \mathrm{c} 62 \mathrm{a}$.

(f) Continuing compute with the remaining steps, if any condition in Table 4 is not satisfied, jump to step (c). If all the conditions are satisfied, go to the second block attack algorithm. We pass the output value $\mathrm{aa}_{0}, \mathrm{bb}_{0}, \mathrm{cc}_{0}$ and $\mathrm{dd}_{0}$ to the second block attack algorithm. 


\subsection{Fast Attack Algorithm for Second Block}

(a) Select random 32-bit value for $m_{0}, m_{1}, m_{2} \ldots m_{13}$

(b) Modify $m_{0}, m_{1}, m_{2} \ldots m_{13}$ by basic message modification technique. We add three extra conditions $\mathrm{d}_{4,21}=1, \mathrm{~d}_{4,22}=1$ and $\mathrm{d}_{4,23}=1$ in $\mathrm{d}_{4}$ for small range searching technique when modifying $\mathrm{m}_{13}$.

(c) Randomly select 32-bit value for $\mathrm{c}_{4}$ but make the conditions $\mathrm{c}_{4,4}=0, \mathrm{c}_{4,16}=0, \mathrm{c}_{4,17}=$ $0, c_{4,25}=1, c_{4,26}=0, c_{4,27}=1, c_{4,28}=1, c_{4,29}=1, c_{4,30}=1$ and $c_{4,31}=1$ hold, then compute the value of $\mathrm{m}_{14}$ :

$\mathrm{m}_{14}=\left[\left(\mathrm{c}_{4}-\mathrm{d}_{4}\right)>>>17\right]-\mathrm{c}_{3}-\mathrm{F}\left(\mathrm{d}_{4}, \mathrm{a}_{4}, \mathrm{~b}_{3}\right)-0$ xa679438e.

Randomly select 32-bit value for $\mathrm{b}_{4}$ but make the conditions $\mathrm{b}_{4,4}=1, \mathrm{~b}_{4,16}=1, \mathrm{~b}_{4,17}=$ $1, \mathrm{~b}_{4,29}=0$ and $\mathrm{b}_{4,32}=\mathrm{c}_{4,32}$ hold, then compute the value of $\mathrm{m}_{15}$ :

$\mathrm{m}_{15}=\left[\left(\mathrm{b}_{4}-\mathrm{c}_{4}\right)>>>22\right]-\mathrm{b}_{3}-\mathrm{F}\left(\mathrm{c}_{4}, \mathrm{~d}_{4}, \mathrm{a}_{4}\right)-0 \mathrm{x} 49 \mathrm{~b} 40821$.

(d) Compute the $17^{\text {th }}$ step:

$\Sigma_{17}=a_{4}+G\left(b_{4}, c_{4}, d_{4}\right)+m_{1}+0 x f 61 e 2562 e \quad a_{5}=b_{4}+\sum_{17}<<<5$.

If conditions $\sum_{17,25} \sim \sum_{17,27}$ not all ones and $a_{5,32}=b_{4,32}$ are not all fulfilled, we search bits $d_{1,4}, d_{1,5}$ in $d_{1}$ and bits $b_{4,21}, b_{4,22}, b_{4,23}^{5,32}, b_{4,24}$ in $b_{4}$, then update the value of $\mathrm{m}_{1}, \mathrm{~m}_{15}\left(\mathrm{~m}_{1}=\left[\left(\mathrm{d}_{1}-\mathrm{a}_{1}\right)>>>12\right]-\mathrm{dd}_{0}-\mathrm{F}\left(\mathrm{a}_{1}, \mathrm{bb}_{0}, \mathrm{cc}_{0}\right)-0 x e 8 \mathrm{c} \mathrm{b} 756, \mathrm{~m}_{15}=\right.$ $\left.\left[\left(b_{4}-c_{4}\right)>>>22\right]-b_{3}-F\left(c_{4}, d_{4}, a_{4}\right)-0 \times 49 b 40821\right)$ to correct them. Compute the $17^{\text {th }}$ step again, if conditions $\mathrm{a}_{5,4}=\mathrm{b}_{4,4}, \mathrm{a}_{5,16}=\mathrm{b}_{4,16}$ and $\mathrm{a}_{5,18}=0$ are not all attained, we search bits $d_{1,11}, d_{1,23}$ and $d_{1,25}$ in $d_{1}$ and update the value of $m_{1}\left(m_{1}=\left[\left(d_{1}-a_{1}\right)\right.\right.$ $>>>12$ ] $\left.-\mathrm{dd}_{0}-\mathrm{F}\left(\mathrm{a}_{1}, \mathrm{bb}_{0}, \mathrm{cc}_{0}\right)-0 \mathrm{xe} 8 \mathrm{c} 7 \mathrm{~b} 756\right)$ to correct them.

(e) Compute the $18^{\text {th }}$ step:

$$
\sum_{18}=d_{4}+G\left(a_{5}, b_{4}, c_{4}\right)+m_{6}+0 x c 040 b 340 \quad d_{5}=a_{5}+\sum_{18}<<<9 .
$$

If conditions $\mathrm{d}_{5,18}=1$ and $\mathrm{d}_{5,32}=\mathrm{a}_{5,32}$ are not all attained, jump to step (c). If $\mathrm{d}_{5,30} \neq \mathrm{a}_{5,30}$, we change bit $\mathrm{c}_{2,6}$ in $\mathrm{c}_{2}$ and update the value of $\mathrm{m}_{6}\left(\mathrm{~m}_{6}=\left[\left(\mathrm{c}_{2}-\mathrm{d}_{2}\right)\right.\right.$ $\left.>>17]-c_{1}-F\left(d_{2}, a_{2}, b_{1}\right)-0 x a 8304613\right)$ to correct it. Then we also need to update the value of $\mathrm{m}_{7}, \mathrm{~m}_{8}, \mathrm{~m}_{9}$ and $\mathrm{m}_{10}$ :

$\mathrm{m}_{7}=\left[\left(\mathrm{b}_{2}-\mathrm{c}_{2}\right)>>>22\right]-\mathrm{b}_{1}-\mathrm{F}\left(\mathrm{c}_{2}, \mathrm{~d}_{2}, \mathrm{a}_{2}\right)-0 \mathrm{xfd} 469501$,

$\mathrm{m}_{8}=\left[\left(\mathrm{a}_{3}-\mathrm{b}_{2}\right)>>>7\right]-\mathrm{a}_{2}-\mathrm{F}\left(\mathrm{b}_{2}, \mathrm{c}_{2}, \mathrm{~d}_{2}\right)-0 \times 698098 \mathrm{~d} 8$,

$\mathrm{m}_{9}=\left[\left(\mathrm{d}_{3}-\mathrm{a}_{3}\right)>>>12\right]-\mathrm{d}_{2}-\mathrm{F}\left(\mathrm{a}_{3}, \mathrm{~b}_{2}, \mathrm{c}_{2}\right)-0 \times 8 \mathrm{~b} 44 \mathrm{f} 7 \mathrm{af}$,

$\mathrm{m}_{10}=\left[\left(\mathrm{c}_{3}-\mathrm{d}_{3}\right)>>>17\right]-\mathrm{c}_{2}-\mathrm{F}\left(\mathrm{d}_{3}, \mathrm{a}_{3}, \mathrm{~b}_{2}\right)-0 x \mathrm{xfff} 5 \mathrm{bb} 1$.

(f) Compute the $19^{\text {th }}$ step:

$$
\sum_{19}=c_{4}+G\left(d_{5}, a_{5}, b_{4}\right)+m_{11}+0 x 265 e 5 a 51 \quad c_{5}=d_{5}+\sum_{19}<<<14 .
$$

If conditions $\sum_{19,4} \sim \sum_{19,18}$ not all ones, $c_{5,18}=0$ and $c_{5,32}=d_{5,32}$ are not all attained, we use small range searching technique to correct them. By searching bits $b_{3,4}, b_{3,5}$, 
$\mathrm{b}_{3,6}, \mathrm{~b}_{3,7}, \mathrm{~b}_{3,21}, \mathrm{~b}_{3,22}, \mathrm{~b}_{3,23}, \mathrm{~b}_{3,24}$ in $\mathrm{b}_{3}$ and update the value of $\mathrm{m}_{11}\left(\mathrm{~m}_{11}=\left[\left(\mathrm{b}_{3}-\mathrm{c}_{3}\right)\right.\right.$ $\left.>>>22]-b_{2}-F\left(c_{3}, d_{3}, a_{3}\right)-0 x 895 c d 7 b e\right)$, we can affect the value of $c_{5}$ to make the conditions $\sum_{19,4} \sim \sum_{19,18}$ not all ones, $c_{5,18}=0, c_{5,32}=d_{5,32}$ hold. Finally, we update the value of $\mathrm{m}_{12}, \mathrm{~m}_{13}, \mathrm{~m}_{14}$ and $\mathrm{m}_{15}$ :

$\mathrm{m}_{12}=\left[\left(\mathrm{a}_{4}-\mathrm{b}_{3}\right)>>>7\right]-\mathrm{a}_{3}-\mathrm{F}\left(\mathrm{b}_{3}, \mathrm{c}_{3}, \mathrm{~d}_{3}\right)-0 \times 6 \mathrm{~b} 901122$,

$\mathrm{m}_{13}=\left[\left(\mathrm{d}_{4}-\mathrm{a}_{4}\right)>>>12\right]-\mathrm{d}_{3}-\mathrm{F}\left(\mathrm{a}_{4}, \mathrm{~b}_{3}, \mathrm{c}_{3}\right)-0 x f d 987193$,

$\mathrm{m}_{14}=\left[\left(\mathrm{c}_{4}-\mathrm{d}_{4}\right)>>>17\right]-\mathrm{c}_{3}-\mathrm{F}\left(\mathrm{d}_{4}, \mathrm{a}_{4}, \mathrm{~b}_{3}\right)-0 \times \mathrm{xa679438}$,

$\mathrm{m}_{15}=\left[\left(\mathrm{b}_{4}-\mathrm{c}_{4}\right)>>>22\right]-\mathrm{b}_{3}-\mathrm{F}\left(\mathrm{c}_{4}, \mathrm{~d}_{4}, \mathrm{a}_{4}\right)-0 \mathrm{x} 49 \mathrm{~b} 40821$.

(g) Compute the $20^{\text {th }}$ step:

$\sum_{20}=b_{4}+G\left(c_{5}, d_{5}, a_{5}\right)+m_{0}+0 x e 9 b 6 c 7 a a \quad b_{5}=c_{5}+\sum_{20}<<<20$.

If conditions $\sum_{20,30} \sim \sum_{20,32}$ not all zeros and $\mathrm{b}_{5,32}=\mathrm{c}_{5,32}$ are not all attained, jump to step (c).

(h) In order to speed up the attack, we want to change the value of $m_{0}$ without updating the value of $m_{1}$, as updating the value of $m_{1}$ will cause the conditions in the $17^{\text {th }}$ step not hold. By randomly select the value of $\mathrm{d}_{1,7}=\mathrm{a}_{1,7}, \mathrm{~d}_{1,8}=\mathrm{a}_{1,8}, \mathrm{~d}_{1,13}=\mathrm{a}_{1,13}$, $\mathrm{d}_{1,18}=\mathrm{a}_{1,18}, \mathrm{~d}_{1,19}=\mathrm{a}_{1,19}, \mathrm{~d}_{1,20}=\mathrm{a}_{1,20}, \mathrm{~d}_{1,21}=\mathrm{a}_{1,21}, \mathrm{~d}_{1,29}=\mathrm{a}_{1,22}, \mathrm{~d}_{1,30}=\mathrm{a}_{1,30}$ and $\mathrm{d}_{1,31}=$ $a_{1,31}$ (see in Table 5), we may change the value of $m_{0}$ without updating the value of $\mathrm{m}_{1}$ if the value of $\mathrm{F}\left(\mathrm{a}_{1}, \mathrm{bb}_{0}, \mathrm{cc}_{0}\right)$ is unchanged. For example, according to the properties of Boolean Function $\mathrm{F}(\mathrm{x}, \mathrm{y}, \mathrm{z})=(\mathrm{x} \wedge \mathrm{y}) \vee(\neg \mathrm{x} \wedge \mathrm{z})[5]$, if $\mathrm{bb}_{0,7}=\mathrm{cc}_{0,7}$, randomly choose the value of $\mathrm{d}_{1,7}=\mathrm{a}_{1,7}$ will not change the value of $\mathrm{F}\left(\mathrm{a}_{1}, \mathrm{bb}_{0}, \mathrm{cc}_{0}\right)$, then the value of $m_{1}\left(m_{1}=\left[\left(d_{1}-a_{1}\right)>>>12\right]-d_{0}-F\left(a_{1}, b_{0}, c_{0}\right)-0 x e 8 c 7 b 756\right)$ will not change at all. After randomly select the values of $d_{1,7}=a_{1,7}, d_{1,8}=a_{1,8}, d_{1,13}$ $=\mathrm{a}_{1,13}, \mathrm{~d}_{1,18}=\mathrm{a}_{1,18}, \mathrm{~d}_{1,19}=\mathrm{a}_{1,19}, \mathrm{~d}_{1,20}=\mathrm{a}_{1,20}, \mathrm{~d}_{1,21}=\mathrm{a}_{1,21}, \mathrm{~d}_{1,29}=\mathrm{a}_{1,29}, \mathrm{~d}_{1,30}=\mathrm{a}_{1,30}$ and $\mathrm{d}_{1,31}=\mathrm{a}_{1,31}$ without changing the value of $\mathrm{m}_{1}$, we update the values of $\mathrm{m}_{0}, \mathrm{~m}_{2}, \mathrm{~m}_{3}$, $\mathrm{m}_{4}$ and $\mathrm{m}_{5}$ :

$\mathrm{m}_{0}^{4}=\left[\left(\mathrm{a}_{1}-\mathrm{bb}_{0}\right)>>>7\right]-\mathrm{aa}_{0}-\mathrm{F}\left(\mathrm{bb}_{0}, \mathrm{cc}_{0}, \mathrm{dd}_{0}\right)-0 \mathrm{xd} 76 \mathrm{aa}_{4} 48$,

$\mathrm{m}_{2}=\left[\left(\mathrm{c}_{1}-\mathrm{d}_{1}\right)>>>17\right]-\mathrm{cc}_{0}-\mathrm{F}\left(\mathrm{d}_{1}, \mathrm{a}_{1}, \mathrm{bb}_{0}\right)-0 \times 242070 \mathrm{db}$,

$\mathrm{m}_{3}=\left[\left(\mathrm{b}_{1}-\mathrm{c}_{1}\right)>>>22\right]-\mathrm{bb}_{0}-\mathrm{F}\left(\mathrm{c}_{1}, \mathrm{~d}_{1}, \mathrm{a}_{1}\right)-0 \mathrm{xc} 1 \mathrm{bdceee}$,

$\mathrm{m}_{4}=\left[\left(\mathrm{a}_{2}-\mathrm{b}_{1}\right)>>>7\right]-\mathrm{a}_{1}-\mathrm{F}\left(\mathrm{b}_{1}, \mathrm{c}_{1}, \mathrm{~d}_{1}\right)-0 x f 57 \mathrm{c} 0 \mathrm{faf}$,

$\mathrm{m}_{5}=\left[\left(\mathrm{d}_{2}-\mathrm{a}_{2}\right)>>>12\right]-\mathrm{d}_{1}-\mathrm{F}\left(\mathrm{a}_{2}, \mathrm{~b}_{1}, \mathrm{c}_{1}\right)-0 \times 4787 \mathrm{c} 62 \mathrm{a}$.

(i) Continuing with the remaining steps of MD5 from step20, if any condition in Table 5 is not satisfied, jump to step (h). If all the possible selections in step (h) fail, then jump to step (c). 


\subsection{The Speed of Our Algorithm}

By using basic message modification technique and small range searching technique, about 35 conditions in round 2-4 are undetermined in the Table 4, and about 31 conditions in round 2-4 are undetermined in the table 5 . Consider the extra conditions, the attack algorithm described in [6] should have about 39 conditions in round 2-4 undetermined in the table 4 and about 34 conditions in round 2-4 undetermined in the table 5. So, using out attack algorithm can speed up the attack of MD5 about 16 times. For each random selection of $a_{5}$ and $b_{5}$ in Fast Attack Algorithm for First Block or $c_{4}$ and $b_{4}$ in Fast Attack Algorithm for Second Block, we can reasonably assume that each random selection for searching takes about 32 steps of MD5 on average, then the first iteration differential holds within $2^{34} \mathrm{MD} 5$ operations, and the second iteration differential holds within $2^{28}$ MD5 operations if ignore conditions $d_{5,18}=1$ and $d_{5,32}=a_{5,32}$ because of their high success probability. The complexity of finding a 1024-bit collision message of MD5 does not exceed the time of running $2^{35}$ MD5 operations.

Compare with the Multi-message Modification technique [7], our small range searching technique should be more efficient for only searching some bits to correct the same conditions in round 2. It seems that the small range searching technique integrates the other two techniques to speed up the attack of MD5. Additionally, our attack algorithm is based on the truly sufficient conditions, we don't need to test whether the characteristics really hold in every step like [6,8], so our attack algorithm could be considered at least 2 times faster than the algorithm present in $[7,8]$.

In experiment, the running time for determining the first block is within 4 hours using a PC with 1.70GHZ Pentium4 CPU, and within 20 minutes for the second block. Thus, we can find an example of MD5 collision within 5 hours. A collision example is given in Table 3 with $\mathrm{c}_{4,32}=\mathrm{b}_{4,32}=\mathrm{a}_{5,32}=\mathrm{d}_{5,32}=\mathrm{c}_{5,32}=\mathrm{b}_{5,32}=\mathrm{a}_{6,32}=\mathrm{d}_{6,32}=1$ for the first iteration.

Table 3. A Collision Example for MD5

\begin{tabular}{|c|c|c|c|c|c|c|c|c|}
\hline IV & 67452301 & efcdab89 & 98badcfe & 10325476 & & & & \\
\hline$M_{0}$ & $\begin{array}{l}\text { 055a604a } \\
\text { 0632ed41 }\end{array}$ & $\begin{array}{l}\text { a3461df0 } \\
\text { 03f3f7fc }\end{array}$ & $\begin{array}{c}12221694 \\
805 \mathrm{eb} 737\end{array}$ & $\begin{array}{r}6 c 449744 \\
1300 \text { af02 }\end{array}$ & $\begin{array}{l}25 c 44 d 2 c \\
\text { befc06c7 }\end{array}$ & $\begin{array}{c}\text { a1b99a33 } \\
0099 \mathrm{e} 023\end{array}$ & $\begin{array}{r}92681957 \\
\text { ff80803f }\end{array}$ & $\begin{array}{l}\text { 3c554e32 } \\
\text { 0000bd93 }\end{array}$ \\
\hline$M_{1}$ & $\begin{array}{l}\text { c0e83a00 } \\
\text { fe32fffd }\end{array}$ & $\begin{array}{l}37 f 3 a f 4 e \\
\text { a7e84fe0 }\end{array}$ & $\begin{array}{l}\text { 95243bff } \\
\text { 30803ffe }\end{array}$ & $\begin{array}{r}\text { f2e16edf } \\
\text { dc833c85 }\end{array}$ & $\begin{array}{l}\text { b4cc3b03 } \\
\text { 5f1330ed }\end{array}$ & $\begin{array}{c}\text { fcbaa5a3 } \\
\text { 088bde83 }\end{array}$ & $\begin{array}{r}852088 \mathrm{e} 8 \\
6 \mathrm{f} 89 \mathrm{~b} 53 \mathrm{~d} \\
\end{array}$ & $\begin{array}{c}\text { c00d7bd1 } \\
819 a 57 f 0\end{array}$ \\
\hline$M_{0}^{\prime}$ & $\begin{array}{l}\text { 055a604a } \\
\text { 0632ed41 }\end{array}$ & $\begin{array}{l}\text { a3461df0 } \\
\text { 03f3f7fc }\end{array}$ & $\begin{array}{c}12221694 \\
805 \mathrm{eb} 737 \\
\end{array}$ & $\begin{array}{c}\text { 6c449744 } \\
13012 f 02 \\
\end{array}$ & $\begin{array}{l}\text { a5c44d2c } \\
\text { befc06c7 }\end{array}$ & $\begin{array}{l}\text { a1b99a33 } \\
0099 \mathrm{e} 023 \\
\end{array}$ & $\begin{array}{l}92681957 \\
7 f 80803 f\end{array}$ & $\begin{array}{c}\text { 3c554e32 } \\
\text { 0000bd93 }\end{array}$ \\
\hline$M_{1}^{\prime}$ & $\begin{array}{l}\text { c0e83a00 } \\
\text { fe32fffd }\end{array}$ & $\begin{array}{l}\text { 37f3af4e } \\
\text { a7e84fe0 }\end{array}$ & $\begin{array}{l}95243 \mathrm{bff} \\
30803 \mathrm{ffe}\end{array}$ & $\begin{array}{l}\text { f2e16edf } \\
\text { dc82bc85 }\end{array}$ & $\begin{array}{c}34 c c 3 b 03 \\
5 f 1330 \text { ed }\end{array}$ & $\begin{array}{c}\text { fcbaa5a3 } \\
\text { 088bde83 }\end{array}$ & $\begin{array}{r}852088 \mathrm{e} 8 \\
\text { ef89b53d }\end{array}$ & $\begin{array}{c}\text { c00d7bd1 } \\
819 a 57 f 0\end{array}$ \\
\hline$H$ & 9cd5a4f9 & 3b375002 & 8са3с972 & 901209ef & & & & \\
\hline
\end{tabular}

\section{Summary}

In this paper, we present an algorithm to speed up the attack of hash function MD5. In order to construct the algorithm, we also discuss the sufficient conditions for keeping 
the two-block collision differential path. By using small range searching technique and omitting the computing steps to check the characteristics, the probability and the complexity to find a collision of MD5 are greatly improved. The small range searching technique can also be used to speed up the attack of other hash functions such as MD4 and RIPEMD.

When we are summarizing our research results, we find that Yu Sasaki etc present their new message modification techniques in [14], they claim that their modification techniques can correct 14 more conditions in round 2 with probability about 1/2. Thus, the complexity is about $2^{33}$ MD5 operations considering the extra conditions in Table 4 and 5. In fact, by random selection of $a_{5}$ and $b_{5}$ in Fast Attack Algorithm for First Block, the conditions $\mathrm{a}_{6,18}=\mathrm{b}_{5,18}, \mathrm{~d}_{6,32}=\mathrm{a}_{6,32}=\mathrm{b}_{5,32}, \mathrm{c}_{6,32}=0, \mathrm{~b}_{6,32}=\mathrm{c}_{6,32}+1$ in round 2 can easily fulfilled with high probability.

\section{References}

1. Ronald Rivest, The MD4 Message Digest Algorithm, RFC1320, April 1992.

2. Ronald Rivest, The MD5 Message Digest Algorithm, RFC1321, April 1992.

3. B. den. Boer, A. Bosselaers, Collisions for the Compression Function of MD5, Advances in Cryptology, EUROCRYPT'93 Proceedings, Springer-Verlag, 1994.

4. H.Dobbertin, Cryptanalysis of MD5 compress, presented at the rump session of Eurocrypt'96.

5. Xiaoyun Wang, Xuejia Lai, Dengguo Feng, et al, Cryptanalysis of the Hash Functions MD4 and RIPEMD, EUROCRYPT 2005, LNCS 3494, pp.1-18, Springer-Verlag, 2005.

6. Xiaoyun Wang, Hongbo $\mathrm{Yu}$, How to Break MD5 and Other Hash Functions, EUROCRYPT 2005, LNCS 3494, pp.19-35, Springer-Verlag, 2005.

7. Vlastimil Klima, Finding MD5 Collisions on a Notebook PC Using Multi-message Modifications, http://eprint.iacr.org/2005/102.pdf, 2005.

8. Patrick Stach, MD5 Collision Generator by Patrick Stach <pstach@stachliu.com>, http://www.stachliu.com.nyud.net:8090/md5coll.c

9. H. Dobbertin. “Cryptanalysis of MD4.” FSE96,pp.53-69,1996.

10. Xiaoyun Wang, Dengguo Feng, Xuejia Lai, Hongbo Yu, Collisions for Hash Functions MD4, MD5, HAVAL-128 and RIPEMD.rump session of Crypto’04, E-print, 2004/199.

11. Vlastimil Klima: Finding MD5 Collisions - a Toy For a Notebook, Cryptology ePrint Archive, Report 2005/075, http://eprint.iacr.org/2005/075.pdf, March 5, 2005.

12. Zhang-yi Wang, Huan-guo Zhang, Zhong-ping Qin, Qing-shu Meng, A Fast Attack on the MD5 Hash Function, paper submitted to The 2nd Information Security Practice and Experience Conference (ISPEC 2006).

13. Jun Yajima, Takeshi Shimoyama, Wang's sufficient conditions of MD5 are not sufficient, http://eprint.iacr.org/2005/263.pdf, 2005.

14. Yu Sasaki* Yusuke Naito* Noboru Kunihiro* Kazuo Ohta*, Improved Collision Attack on MD5, http://eprint.iacr.org/2005/400.pdf, 2005. 


\section{Appendices}

Table 4. A set of Sufficient Conditions for the First Iteration Differential

\begin{tabular}{|c|c|}
\hline$c_{1,7}=0, c_{1,12}=0, c_{1,20}=0$ & Extra conditions derived from $\sum_{i}$ \\
\hline $\begin{array}{l}\mathrm{b}_{1,7}=0, \mathrm{~b}_{1,8}=\mathrm{c}_{1,8}, \mathrm{~b}_{1,9}=\mathrm{c}_{1,9}, \mathrm{~b}_{1,10}=\mathrm{c}_{1,10}, \mathrm{~b}_{1,11}=\mathrm{c}_{1,11}, \mathrm{~b}_{1,12}=1, \mathrm{~b}_{1,13}=\mathrm{c}_{1,13}, \\
\mathrm{~b}_{1,14}=\mathrm{c}_{1,14}, \mathrm{~b}_{1,15}=\mathrm{c}_{1,15}, \mathrm{~b}_{1,16}=\mathrm{c}_{1,16}, \mathrm{~b}_{1,17}=\mathrm{c}_{1,17} \mathrm{~b}_{1,18}=\mathrm{c}_{1,18}, \mathrm{~b}_{1,19}=\mathrm{c}_{1,19} \\
\mathrm{~b}_{1,20}=1, \mathrm{~b}_{1,21}=\mathrm{c}_{1,21}, \mathrm{~b}_{1,22}=\mathrm{c}_{1,22}, \mathrm{~b}_{1,23}=\mathrm{c}_{1,23}, \mathrm{~b}_{1,24}^{=}=0, \mathrm{~b}_{1,32}=1\end{array}$ & $\sum_{5} \Rightarrow b_{1,5}=1, b_{1,6}=1, a_{2,5}=0$ \\
\hline $\begin{array}{l}\mathrm{a}_{2,1}=1, \mathrm{a}_{2,3}=1, \mathrm{a}_{2,6}=1, \mathrm{a}_{2,7}=0, \mathrm{a}_{2,8}=0, \mathrm{a}_{2,9}=0, \mathrm{a}_{2,10}=0, \mathrm{a}_{2,11}=0, \mathrm{a}_{2,12}=0, \\
\mathrm{a}_{2,13}=0, \mathrm{a}_{2,14}=0, \mathrm{a}_{2,15}=0, \mathrm{a}_{2,16}=0, \mathrm{a}_{2,17}=0, \mathrm{a}_{2,18}=0, \mathrm{a}_{2,19}=0, \mathrm{a}_{2,20}=0, \\
\mathrm{a}_{2,21}=0, \mathrm{a}_{2,22}=0, \mathrm{a}_{2,23}=1, \mathrm{a}_{2,24}=0, \mathrm{a}_{2,26}=0, \mathrm{a}_{2,28}=1, \mathrm{a}_{2,32}=1\end{array}$ & $\begin{aligned} \sum_{7} \Rightarrow a_{2,27} & =0, a_{2,29}=0 \\
a_{2,30} & =0, a_{2,31}=0\end{aligned}$ \\
\hline $\begin{array}{l}\mathrm{d}_{2,1}=1, \mathrm{~d}_{2,2}=\mathrm{a}_{2,2}, \mathrm{~d}_{2,3}=0, \mathrm{~d}_{2,4}=\mathrm{a}_{2,4}, \mathrm{~d}_{2,5}=\mathrm{a}_{2,5}, \mathrm{~d}_{2,6}=0, \mathrm{~d}_{2,7}=1, \mathrm{c} \\
=1, \mathrm{~d}_{2,13}=1, \mathrm{~d}_{2,14}=1, \mathrm{~d}_{2,15}=0, \mathrm{~d}_{2,16}=1, \mathrm{~d}_{2,17}=1, \mathrm{~d}_{2,18}=1, \mathrm{~d}_{2,19}=1 \\
\mathrm{~d}_{2,24}=0, \mathrm{~d}_{2,25}=\mathrm{a}_{2,25}, \mathrm{~d}_{2,26}=1, \mathrm{~d}_{2,27}=\mathrm{a}_{2,27}, \mathrm{~d}_{2,28}=0, \mathrm{~d}_{2,29}=\mathrm{a}_{2,29}, \mathrm{~d}_{2,30}=\end{array}$ & $\begin{array}{l}=0, d_{2,9}=0, d_{2,10}=0, d_{2,11}=1, d_{2,12} \\
d_{2,20}=1, d_{2,21}=1, d_{2,22}=1, d_{2,23}=1, \\
2,30 \\
d_{2,31}=a_{2,31}, d_{2,32}=0\end{array}$ \\
\hline $\begin{array}{l}c_{2,1}=0, c_{2,2}=0, c_{2,3}=0, c_{2,4}=0, c_{2,5}=0, c_{2,6}=1, c_{2,7}=0, c_{2,8}=0, c_{2} \\
1, c_{2,14}=1, c_{2,15}=1, c_{2,16}=1, c_{2,17}=0, c_{2,18}=1, c_{2,19}=1, c_{2,20}=1, c_{2,2} \\
1, c_{2,26}=1, c_{2,27}=0, c_{2,28}=0, c_{2,29}=0, c_{2,30}=0, c_{2,31}=0, c_{2,32}=0\end{array}$ & $\begin{array}{l}=0, c_{2,10}=0, c_{2,11}=0, c_{2,12}=1, c_{2,13}= \\
=1, c_{2,22}=1, c_{2,23}=1, c_{2,24}=1, c_{2,25}=\end{array}$ \\
\hline $\begin{array}{l}\mathrm{b}_{2,1}=0, \mathrm{~b}_{2,2}=0, \mathrm{~b}_{2,3}=0, \mathrm{~b}_{2,4}=0, \mathrm{~b}_{2,5}=0, \mathrm{~b}_{2,6}=0, \mathrm{~b}_{2,7}=1, \mathrm{~b}_{2,8}=0, \mathrm{~b}_{2,9} \\
\mathrm{~b}_{2,16}=0, \mathrm{~b}_{2,17}=1, \mathrm{~b}_{2,18}=0, \mathrm{~b}_{2,19}=0, \mathrm{~b}_{2,20}=0, \mathrm{~b}_{2,21}=1, \mathrm{~b}_{2,24}=1, \mathrm{~b}_{2,25} \\
\mathrm{~b}_{2,30}=0, \mathrm{~b}_{2,31}=0, \mathrm{~b}_{2,32}=0\end{array}$ & $\begin{array}{l}=1, b_{2,10}=0, b_{2,11}=1, b_{2,12}=0, b_{2,14}=0, \\
1, b_{2,26}=0, b_{2,27}=0, b_{2,28}=0, b_{2,29}=0,\end{array}$ \\
\hline $\begin{array}{l}a_{3,1}=1, a_{3,2}=0, a_{3,3}=1, a_{3,4}=1, a_{3,5}=1, a_{3,6}=1, a_{3,7}=0, a_{3,8}=0, a_{3,9}=1, a_{3,} \\
a_{3,16}=0, a_{3,17}=0, a_{3,18}=0, a_{3,19}=0, a_{3,20}=0, a_{3,21}=1, a_{3,25}=1, a_{3,26}=1, a_{3,27}=0, a^{2}\end{array}$ & $\begin{array}{l}=1, a_{3,11}=1, a_{3,12}=1, a_{3,13}=b_{3,13}, a_{3,14}=1, \\
=1, a_{3,29}=1, a_{3,30}=1, a_{3,31}=1, a_{3,32}=1\end{array}$ \\
\hline $\begin{array}{l}d_{3,1}=0, d_{3,2}=0, d_{3,7}=1, d_{3,8}=0, d_{3,9}=0, d_{3,13}=1, d_{3,14}=0, d_{3,16}=1 \\
d_{3,17}=1, d_{3,18}=1, d_{3,19}=1, d_{3,20}=1, d_{3,21}=1, d_{3,24}=0, d_{3,31}=1, d_{3,32}=0\end{array}$ & $\begin{array}{c}\sum_{11} \Rightarrow d_{3,29}=1, d_{3,30}=1 \\
c_{3,29}=0, c_{3,30}=1\end{array}$ \\
\hline \multicolumn{2}{|c|}{$\begin{array}{l}\mathrm{c}_{3,1}=0, \mathrm{c}_{3,2}=1, \mathrm{c}_{3,7}=1, \mathrm{c}_{3,8}=1, \mathrm{c}_{3,9}=0, \mathrm{c}_{3,13}=0, \mathrm{c}_{3,14}=0, \mathrm{c}_{3,15}=\mathrm{d}_{3,15}, \mathrm{c}_{3,16}=1, \mathrm{c}_{3,17}=1, \mathrm{c}_{3,18}=0, \mathrm{c}_{3,19}=0, \\
\mathrm{c}_{3,20}=0, \mathrm{c}_{3,31}=0, \mathrm{c}_{3,32}=0\end{array}$} \\
\hline $\begin{array}{l}\mathrm{b}_{3,8}=0, \mathrm{~b}_{3,9}=1, \mathrm{~b}_{3,13}=1, \mathrm{~b}_{3,14}=0, \mathrm{~b}_{3,15}=0, \mathrm{~b}_{3,16}=0, \mathrm{~b}_{3,17}=0 \\
\mathrm{~b}_{3,18}=0, \mathrm{~b}_{3,20}=1, \mathrm{~b}_{3,25}=\mathrm{c}_{3,25}, \mathrm{~b}_{3,26}=\mathrm{c}_{3,26}, \mathrm{~b}_{3,19}=0, \mathrm{~b}_{3,31}=0, \mathrm{~b}_{3,32}=0\end{array}$ & $\sum_{12} \Rightarrow b_{3,30}=0$ \\
\hline \multicolumn{2}{|c|}{$\mathrm{a}_{4,4}=1, \mathrm{a}_{4,8}=0, \mathrm{a}_{4,9}=0, \mathrm{a}_{4,14}=1, \mathrm{a}_{4,15}=1, \mathrm{a}_{4,16}=1, \mathrm{a}_{4,17}=1, \mathrm{a}_{4,18}=1, \mathrm{a}_{4,19}=1, \mathrm{a}_{4,20}=1, \mathrm{a}_{4,25}=1, \mathrm{a}_{4,26}=0, \mathrm{a}_{4,31}=1, \mathrm{a}_{4,32}=0$} \\
\hline $\begin{array}{l}\mathrm{d}_{4,4}=1, \mathrm{~d}_{4,8}=1, \mathrm{~d}_{4,9}=1, \mathrm{~d}_{4,14}=1, \mathrm{~d}_{4,15}=1, \mathrm{~d}_{4,16}=1, \mathrm{~d}_{4,17}=1, \mathrm{~d}_{4,18} \\
=1, \mathrm{~d}_{4,19}=0, \mathrm{~d}_{4,20}=1, \mathrm{~d}_{4,25}=0, \mathrm{~d}_{4,26}=0, \mathrm{~d}_{4,30}=0, \mathrm{~d}_{4,32}=0\end{array}$ & $\sum_{14} \Rightarrow d_{4,31}=0$ \\
\hline $\mathrm{c}_{4,4}=0, \mathrm{c}_{4,16}=1, \mathrm{c}_{4,25}=1, \mathrm{c}_{4,26}=0, \mathrm{c}_{4,30}=1$ & $\sum_{15} \Rightarrow c_{4,15}=0$ \\
\hline $\mathrm{b}_{4,30}=1, \mathrm{~b}_{4,32}=\mathrm{c}_{4,32}$ & $\sum_{16} \Rightarrow c_{4,31}=1, b_{4,22}=c_{4,22}+1, b_{4,31}=0$ \\
\hline $\mathrm{a}_{5,4}=\mathrm{b}_{4,4}, \mathrm{a}_{5,16}=\mathrm{b}_{4,16}, \mathrm{a}_{5,18}=0, \mathrm{a}_{5,32}=\mathrm{b}_{4,32}$ & $\sum_{17} \Rightarrow a_{5,31}=b_{4,31}+1=1$ \\
\hline $\mathrm{d}_{5,18}=1, \mathrm{~d}_{5,30}=\mathrm{a}_{5,30}, \mathrm{~d}_{5,32}=\mathrm{a}_{5,32}, \mathrm{c}_{5,18}=0, \mathrm{c}_{5,32}=\mathrm{d}_{5,32}$ & $\sum_{19,4} \sim \sum_{19,18}$ not all ones \\
\hline $\mathrm{b}_{5,32}=\mathrm{c}_{5,32}$ & $\sum_{20,30} \sim \sum_{20,32}$ not all zeros \\
\hline $\mathrm{a}_{6,18}=\mathrm{b}_{5,18}, \mathrm{~d}_{6,32}=\mathrm{a}_{6,32}=\mathrm{b}_{5,32}, \mathrm{c}_{6,32}=0, \mathrm{~b}_{6,32}=\mathrm{c}_{6,32}+1, \mathrm{~b}_{12,32}=\mathrm{d}_{12,32}$ & $\sum_{23,18}=0, \quad \sum_{35,16}=0$ \\
\hline $\begin{array}{l}\mathrm{a}_{13,32}=\mathrm{c}_{12,32}, \mathrm{~d}_{13,32}=\mathrm{b}_{12,32}+1, \mathrm{c}_{13,32}=\mathrm{a}_{13,32}, \mathrm{~b}_{13,32}=\mathrm{d}_{13,32}, \mathrm{a}_{14,32}=\mathrm{c}_{13,32}, \\
\mathrm{a}_{15,32}=\mathrm{c}_{14,32}, \mathrm{~d}_{15,32}=\mathrm{b}_{14,32}, \mathrm{c}_{15,32}=\mathrm{a}_{15,32}, \mathrm{~b}_{15,26}=0, \mathrm{~b}_{15,32}=\mathrm{d}_{15,32}+1, \mathrm{1}\end{array}$ & $\begin{array}{l}\mathrm{d}_{14,32}=\mathrm{b}_{13,32}, \mathrm{c}_{14,32}=\mathrm{a}_{14,32}, \mathrm{~b}_{14,32}=\mathrm{d}_{14,32} \\
=1, \mathrm{a}_{16,32}=\mathrm{c}_{15,32}\end{array}$ \\
\hline $\mathrm{dd}_{0,26}=0, \mathrm{~d}_{16,26}=0, \mathrm{~d}_{16,32}=\mathrm{b}_{15,32}$ & $\sum_{62,16} \sim \sum_{62,22}$ not all ones \\
\hline $\mathrm{cc}_{0,26}=1, \mathrm{cc}_{0,27}=0, \mathrm{c}_{16,26}=0, \mathrm{c}_{16,32}=\mathrm{a}_{16,32}, \mathrm{bb}_{0,26}=0, \mathrm{bb}_{0,27}=0, \mathrm{bb}_{0,6}=$ & $0, \mathrm{bb}_{0,32}=\mathrm{cc}_{0,32}=\mathrm{dd}_{0,32}$ \\
\hline
\end{tabular}


Table 5.A set of Sufficient Conditions for the Second Iteration Differential

\begin{tabular}{|c|c|}
\hline $\mathrm{a}_{1,6}=0, \mathrm{a}_{1,12}=0, \mathrm{a}_{1,22}=1, \mathrm{a}_{1,26}=0, \mathrm{a}_{1,27}=1, \mathrm{a}_{1,28}=0, \mathrm{a}_{1,32}=\mathrm{bb}_{0,32}+1$ & Extra conditions derived from $\sum_{i}$ \\
\hline $\begin{array}{l}\mathrm{d}_{1,2}=0, \mathrm{~d}_{1,3}=0, \mathrm{~d}_{1,6}=0, \mathrm{~d}_{1,7}=\mathrm{a}_{1,7}, \mathrm{~d}_{1,8}=\mathrm{a}_{1,8}, \mathrm{~d}_{1,12}=1, \mathrm{~d}_{1,13}=\mathrm{a}_{1,13}, \mathrm{~d}_{1,17}=1, \\
\mathrm{~d}_{1,18}=\mathrm{a}_{1,18}, \mathrm{~d}_{1,19}=\mathrm{a}_{1,19}, \mathrm{~d}_{1,20}=\mathrm{a}_{1,20}, \mathrm{~d}_{1,21}=\mathrm{a}_{1,21}, \mathrm{~d}_{1,22}=0, \mathrm{~d}_{1,26}=0, \mathrm{~d}_{1,27}=1, \\
\mathrm{~d}_{1,28}=1, \mathrm{~d}_{1,29}=\mathrm{a}_{1,29}, \mathrm{~d}_{1,30}=\mathrm{a}_{1,30}, \mathrm{~d}_{1,31}=\mathrm{a}_{1,31}, \mathrm{~d}_{1,32}=\mathrm{a}_{1,32}\end{array}$ & $\Sigma_{3} \Rightarrow a_{1,17}=1, d_{1,16}=0, c_{1,16}=1$ \\
\hline $\begin{array}{l}c_{1,2}=1, c_{1,3}=1, c_{1,4}=d_{1,4}, c_{1,5}=d_{1,5}, c_{1,6}=1, c_{1,7}=1, c_{1,8}=0, c_{1,9}=1, \\
c_{1,12}=1, c_{1,13}=0, c_{1,17}=1, c_{1,18}=1, c_{1,19}=1, c_{1,20}=1, c_{1,21}=1, c_{1,22}=0, \\
c_{1,26}=1, c_{1,27}=1, c_{1,28}=1, c_{1,29}=1, c_{1,30}=1, c_{1,31}=0, c_{1,32}=d_{1,32}\end{array}$ & $\sum_{5} \Rightarrow c_{1,1}=1$ \\
\hline $\begin{array}{l}\mathrm{b}_{1,1}=1, \mathrm{~b}_{1,2}=0, \mathrm{~b}_{1,3}=0, \mathrm{~b}_{1,4}=0, \mathrm{~b}_{1,5}=1, \mathrm{~b}_{1,6}=0, \mathrm{~b}_{1,7}=0, \mathrm{~b}_{1,8}=0, \mathrm{~b}_{1,9}= \\
\mathrm{b}_{1,17}=0, \mathrm{~b}_{1,18}=0, \mathrm{~b}_{1,19}=1, \mathrm{~b}_{1,20}=0, \mathrm{~b}_{1,21}=0, \mathrm{~b}_{1,22}=0, \mathrm{~b}_{1,26}=1, \mathrm{~b}_{1,27}=0, \mathrm{~b}_{1,28}=\end{array}$ & $\begin{array}{l}\mathrm{b}_{1,10}=\mathrm{c}_{1,10}, \mathrm{~b}_{1,11}=\mathrm{c}_{1,11}, \mathrm{~b}_{1,12}=0, \mathrm{~b}_{1,13}=0, \\
\mathrm{~b}_{1,29}=1, \mathrm{~b}_{1,30}=1, \mathrm{~b}_{1,31}=0, \mathrm{~b}_{1,32}=\mathrm{c}_{1,32}\end{array}$ \\
\hline $\begin{array}{l}\mathrm{a}_{2,1}=0, \mathrm{a}_{2,2}=0, \mathrm{a}_{2,3}=0, \mathrm{a}_{2,4}=0, \mathrm{a}_{2,5}=1, \mathrm{a}_{2,6}=0, \mathrm{a}_{2,7}=1, \mathrm{a}_{2,8}=0, \mathrm{a}_{2,9}=0, \\
\mathrm{a}_{2,10}=1, \mathrm{a}_{2,11}=1, \mathrm{a}_{2,12}=1, \mathrm{a}_{2,13}=0, \mathrm{a}_{2,17}=1, \mathrm{a}_{2,18}=1, \mathrm{a}_{2,19}=1, \mathrm{a}_{2,20}=1, \\
\mathrm{a}_{2,21}=0, \mathrm{a}_{2,22}=1, \mathrm{a}_{2,27}=0, \mathrm{a}_{2,28}=1, \mathrm{a}_{2,29}=0, \mathrm{a}_{2,30}=0, \mathrm{a}_{2,31}=1, \mathrm{a}_{2,32}=\mathrm{b}_{1,32}+1\end{array}$ & $\sum_{7} \Rightarrow \mathrm{d}_{2,15}=1, \mathrm{c}_{2,15}=0$ \\
\hline $\begin{array}{l}\mathrm{d}_{2,1}=0, \mathrm{~d}_{2,2}=1, \mathrm{~d}_{2,3}=1, \mathrm{~d}_{2,4}=0, \mathrm{~d}_{2,5}=1, \mathrm{~d}_{2,6}=0, \mathrm{~d}_{2,7}=1, \mathrm{~d}_{2,8}= \\
\mathrm{d}_{2,13}=0, \mathrm{~d}_{2,17}=0, \mathrm{~d}_{2,18}=1, \mathrm{~d}_{2,21}=0, \mathrm{~d}_{2,22}=1, \mathrm{~d}_{2,26}=0, \mathrm{~d}_{2,27}=1, \mathrm{~d}_{2,28}\end{array}$ & $\begin{array}{l}0, d_{2,9}=0, d_{2,10}=0, d_{2,11}=1, d_{2,12}=1 \\
0, d_{2,29}=0, d_{2,32}=a_{2,32}\end{array}$ \\
\hline $\begin{array}{l}c_{2,1}=1, c_{2,7}=0, c_{2,8}=0, c_{2,9}=0, c_{2,10}=1, c_{2,11}=1, c_{2,12}=1, c_{2,13}= \\
c_{2,22}=0, c_{2,24}=d_{2,24}, c_{2,25}=d_{2,25}, c_{2,26}=1, c_{2,27}=1, c_{2,28}=0, c_{2,29}=1, c^{2}\end{array}$ & $\begin{array}{l}\mathrm{c}_{2,16}=\mathrm{d}_{2,16}, \mathrm{c}_{2,17}=1, \mathrm{c}_{2,18}=0, \mathrm{c}_{2,21}=0 \\
=\mathrm{d}_{2,32}+1\end{array}$ \\
\hline $\begin{array}{l}\mathrm{b}_{2,1}=0, \mathrm{~b}_{2,2}=\mathrm{c}_{2,2}, \mathrm{~b}_{2,7}=1, \mathrm{~b}_{2,8}=1, \mathrm{~b}_{2,9}=1, \mathrm{~b}_{2,10}=1, \mathrm{~b}_{2,16}=1, \mathrm{~b} \underset{2,17}{=}=0, \mathrm{~b}_{2,18}=1, \\
\mathrm{~b}_{2,21}=1, \mathrm{~b}_{2,22}=1, \mathrm{~b}_{2,24}=0, \mathrm{~b}_{2,25}=0, \mathrm{~b}_{2,26}=0, \mathrm{~b}_{2,27}=1, \mathrm{~b}_{2,28}=0, \mathrm{~b}_{2,29}=0, \mathrm{~b}_{2,32}=\mathrm{C}_{2,32}\end{array}$ & $\sum_{9} \Rightarrow b_{2,6}=1, a_{3,6}=0$ \\
\hline $\begin{array}{l}\mathrm{a}_{3,1}=1, \mathrm{a}_{3,2}=0, \mathrm{a}_{3,7}=1, \mathrm{a}_{3,8}=1, \mathrm{a}_{3,9}=1, \mathrm{a}_{3,10}=0, \mathrm{a}_{3,13}=\mathrm{b}_{2,13}, \mathrm{a}_{3,16} \\
\mathrm{a}_{3,26}=0, \mathrm{a}_{3,27}=1, \mathrm{a}_{3,28}=1, \mathrm{a}_{3,29}=1, \mathrm{a}_{3,32}=\mathrm{b}_{2,32}\end{array}$ & $0, a_{3,17}=1, a_{3,18}=0, a_{3,24}=0, a_{3,25}=0$ \\
\hline $\begin{array}{l}\mathrm{d}_{3,1}=0, \mathrm{~d}_{3,2}=0, \mathrm{~d}_{3,7}=1, \mathrm{~d}_{3,8}=1, \mathrm{~d}_{3,9}=1, \mathrm{~d}_{3,10}=1, \mathrm{~d}_{3,13}=0, \mathrm{~d}_{3,16}=1, \\
\mathrm{~d}_{3,17}=1, \mathrm{~d}_{3,18}=1, \mathrm{~d}_{3,19}=0, \mathrm{~d}_{3,24}=1, \mathrm{~d}_{3,25}=1, \mathrm{~d}_{3,26}=1, \mathrm{~d}_{3,27}=1, \mathrm{~d}_{3,32}=\mathrm{a}_{3,32}\end{array}$ & $\sum_{11} \Rightarrow \mathrm{d}_{3,12}=1, \mathrm{c}_{3,12}=0$ \\
\hline \multicolumn{2}{|c|}{$\begin{array}{l}c_{3,1}=1, c_{3,2}=1, c_{3,7}=1, c_{3,8}=1, c_{3,9}=1, c_{3,10}=1, c_{3,13}=0, c_{3,14}=d_{3,14}, c_{3,15}=d_{3,15}, c_{3,16}=1, c_{3,17}=1, \\
c_{3,18}=0, c_{3,19}=1, c_{3,20}=d_{3,20}, c_{3,32}=d_{3,32}\end{array}$} \\
\hline \multicolumn{2}{|c|}{$\begin{array}{l}\mathrm{b}_{3,8}=1, \mathrm{~b}_{3,13}=1, \mathrm{~b}_{3,14}=0, \mathrm{~b}_{3,15}=0, \mathrm{~b}_{3,16}=0, \mathrm{~b}_{3,17}=0, \mathrm{~b}_{3,18}=0, \mathrm{~b}_{3,19}=0, \mathrm{~b}_{3,20}=1, \mathrm{~b}_{3,25}=\mathrm{c}_{3,25}, \mathrm{~b}_{3,26}=\mathrm{c}_{3,26}, \\
\mathrm{~b}_{3,27}=\mathrm{c}_{3,27}, \mathrm{~b}_{3,28}=\mathrm{c}_{3,28}, \mathrm{~b}_{3,29}=\mathrm{c}_{3,29}, \mathrm{~b}_{3,30}=\mathrm{c}_{3,30}, \mathrm{~b}_{3,31}=\mathrm{c}_{3,31}, \mathrm{~b}_{3,32}=\mathrm{c}_{3,32}\end{array}$} \\
\hline $\begin{array}{l}\mathrm{a}_{4,4}=1, \mathrm{a}_{4,8}=0, \mathrm{a}_{4,14}=1, \mathrm{a}_{4,15}=1, \mathrm{a}_{4,16}=1, \mathrm{a}_{4,17}=1, \mathrm{a}_{4,18}=1, \mathrm{a}_{4,19}=1, \mathrm{a}_{4,20}=1 \\
\mathrm{a}_{4,25}=1, \mathrm{a}_{4,26}=1, \mathrm{a}_{4,27}=1, \mathrm{a}_{4,28}=1, \mathrm{a}_{4,29}=1, \mathrm{a}_{4,30}=1, \mathrm{a}_{4,31}=0, \mathrm{a}_{4,32}=\mathrm{b}_{3,32}+1\end{array}$ & $\sum_{14} \Rightarrow \mathrm{a}_{4,24}=0, \mathrm{~d}_{4,24}=1$ \\
\hline $\begin{array}{l}\mathrm{d}_{4,4}=1, \mathrm{~d}_{4,8}=1, \mathrm{~d}_{4,14}=1, \mathrm{~d}_{4,15}=1, \mathrm{~d}_{4,16}=1, \mathrm{~d}_{4,17}=1, \mathrm{~d}_{4,18}=1, \mathrm{~d}_{4,19}= \\
\mathrm{d}_{4,28}=0, \mathrm{~d}_{4,29}=0, \mathrm{~d}_{4,30}=0, \mathrm{~d}_{4,31}=1, \mathrm{~d}_{4,32}=\mathrm{a}_{4,32}\end{array}$ & $\mathrm{~d}_{4,20}=1 \mathrm{~d}_{4,25}=0, \mathrm{~d}_{4,26}=0, \mathrm{~d}_{4,27}=0$ \\
\hline $\mathrm{c}_{4,4}=0, \mathrm{c}_{4,16}=0, \mathrm{c}_{4,25}=1, \mathrm{c}_{4,26}=0, \mathrm{c}_{4,27}=1, \mathrm{c}_{4,28}=1, \mathrm{c}_{4,29}=1, \mathrm{c}_{4,30}=1, \mathrm{c}_{4,31}=1$ & $\sum_{15} \Rightarrow c_{4,17}=0$ \\
\hline $\mathrm{b}_{4,4}=1, \mathrm{~b}_{4,32}=\mathrm{c}_{4,32}$ & $\sum_{16} \Rightarrow b_{4,16}=1, b_{4,17}=1, b_{4,29}=0$ \\
\hline $\mathrm{a}_{5,4}=\mathrm{b}_{4,4}, \mathrm{a}_{5,16}=\mathrm{b}_{4,16}, \mathrm{a}_{5,18}=0, \mathrm{a}_{5,32}=\mathrm{b}_{4,32}$ & $\sum_{17,25} \sim \sum_{17,27}$ not all ones \\
\hline $\mathrm{d}_{5,18}=1, \mathrm{~d}_{5,30}=\mathrm{a}_{5,30}, \mathrm{~d}_{5,32}=\mathrm{a}_{5,32}, \mathrm{c}_{5,18}=0, \mathrm{c}_{5,32}=\mathrm{d}_{5,32}$ & $\sum_{19,4} \sim \sum_{19,18}$ not all ones \\
\hline $\mathrm{b}_{5,32}=\mathrm{c}_{5,32}$ & $\sum_{20,30} \sim \sum_{20,32}$ not all zeros \\
\hline $\mathrm{a}_{6,18}=\mathrm{b}_{5,18}, \mathrm{~d}_{6,32}=\mathrm{a}_{6,32}=\mathrm{b}_{5,32}, \mathrm{c}_{6,32}=0, \mathrm{~b}_{6,32}=\mathrm{c}_{6,32}+1, \mathrm{~b}_{12,32}=\mathrm{d}_{12,32}$ & $\sum_{23,18}=0, \quad \sum_{35,16}=1$ \\
\hline $\begin{array}{l}\mathrm{a}_{13,32}=\mathrm{c}_{12,32}, \mathrm{~d}_{13,32}=\mathrm{b}_{12,32}+1, \mathrm{c}_{13,32}=\mathrm{a}_{13,32}, \mathrm{~b}_{13,32}=\mathrm{d}_{13,32}, \mathrm{a}_{14,32}=\mathrm{c}_{13,3} \\
\mathrm{~b}_{14,32}=\mathrm{d}_{14,32}, \mathrm{a}_{15,32}=\mathrm{c}_{14,32}, \mathrm{~d}_{15,32}=\mathrm{b}_{14,32}, \mathrm{c}_{15,32}=\mathrm{a}_{15,32}, \mathrm{~b}_{15,26}=0, \mathrm{~b}_{15,32}\end{array}$ & $\begin{array}{l}d_{14,32}=b_{13,32}, c_{14,32}=a_{14,32}, \\
d_{15,32}+1, a_{16,26}=1, a_{16,32}=c_{15,32}\end{array}$ \\
\hline $\mathrm{d}_{16,26}=1, \mathrm{~d}_{16,32}=\mathrm{b}_{15,32}, \mathrm{c}_{16,26}=1, \mathrm{c}_{16,32}=\mathrm{a}_{16,32}, \mathrm{~b}_{16,26}=1$ & $\sum_{62,16} \sim \sum_{62,22}$ not all zeros \\
\hline
\end{tabular}


Table 6. A Counterexample Satisfied Cnditions in Table 5 Ecept for $\mathrm{b}_{15,26}=1$

\begin{tabular}{|c|llllllll|}
\hline$H_{1}$ & aa14309f & 80820546 & c273be7a & cdc25be6 & & & & \\
\hline \multirow{2}{*}{$M_{1}$} & $\begin{array}{l}\text { e4473624 } \\
\text { bdfbfefd }\end{array}$ & 7f00fd6 & 9d285199 & 42a37cde & 4513f7ff & 4cadc2fe & a6208936 & c2027bcd \\
& 4420063 & fef41cbe & 7f3b44f & 580a4fb2 & a21a69f2 \\
\hline$H_{2}$ & d0fa79d & fa896b4e & 8d8d224 & 81a9a7d9 & & & & \\
\hline$H_{1}^{\prime}$ & 2a14309f & 2820546 & $4473 b e 7 a$ & $4 f c 25 b e 6$ & & & & \\
\hline \multirow{2}{*}{$M_{1}^{\prime}$} & $\begin{array}{l}\text { e4473624 } \\
\text { bdfbfefd }\end{array}$ & 7fc3d164 & 9d285199 & 42a37cde & c513f7f9 & 4cadc2fe & a6208936 & c2027bcd \\
\hline$H_{2}^{\prime}$ & d0fa79d & ba896c4e & 8d8df324 & 81a9a7d9 & & & & \\
\hline
\end{tabular}

Table 7. A Collision Example for The First Block with $\mathrm{a}_{16,27}=1$

\begin{tabular}{|c|llllllll|}
\hline$I V$ & 67452301 & efcdab89 & 98badcfe & 10325476 \\
\hline \multirow{2}{*}{$M_{0}$} & 10e53c6b & 57e8f46b & e861c5ea & $5736 e 652$ & 51c3a485 & e111fe10 & 939aa559 & e9039a39 \\
& 6332d51 & 2341c04 & 82b0fb4b & $57 \mathrm{~b} 2 \mathrm{e} 311$ & 429126e3 & 4a8c20db & 62ce4193 & 52823034 \\
\hline \multirow{2}{*}{$H^{\prime}$} & cdb59525 & 90550918 & b204dbce & 99a80f8f & & & & \\
\hline \multirow{2}{*}{$M_{0}^{\prime}$} & 10e53c6b & $57 \mathrm{e} 8 \mathrm{f} 46 \mathrm{~b}$ & e861c5ea & $5736 \mathrm{e} 652$ & d1c3a485 & e111fe10 & 939aa559 & e9039a39 \\
& 6332d51 & 2341c04 & 82b0fb4b & $57 \mathrm{~b} 36311$ & 429126e3 & 4a8c20db & e2ce4193 & 52823034 \\
\hline$H^{\prime}$ & 4db59525 & 12550918 & 3404dbce & 1ba80f8f & & & & \\
\hline
\end{tabular}

Table 8. A Counterexample Satisfied Cnditions in Table 4 Ecept for $c_{16,32}=d_{16,32} \neq a_{16,32}$

\begin{tabular}{|c|cccccccc|}
\hline$I V$ & 67452301 & efcdab89 & 98badcfe & 10325476 & & & & \\
\hline \multirow{2}{*}{$M_{0}$} & b3ff8745 & c72eb352 & 5f2ff952 & a9b33ceb & fc7993f8 & b7687688 & c1548362 & 8180b92e \\
& 6342d45 & 23f43bfd & 7c42a22f & 14a14334 & 332550f3 & 34ab42c4 & $7423620 c$ & 341f42b4 \\
\hline \multirow{2}{*}{$H^{\prime}$} & a9a392c8 & 6118e81d & 7a12d3b4 & d116e78 & & & & \\
\hline \multirow{2}{*}{$M_{0}^{\prime}$} & b3ff8745 & c72eb352 & 5f2ff952 & a9b33ceb & 7c7993f8 & b7687688 & c1548362 & 8180b92e \\
\hline$H^{\prime}$ & 6342d45 & 23f43bfd & 7c42a22f & 14a1c334 & 332550f3 & 34ab42c4 & f423620c & 341f42b4 \\
\hline
\end{tabular}

Table 9. A Counterexample Satisfied Cnditions in Table 4 Ecept for $\mathrm{d}_{16,26}=1$

\begin{tabular}{|c|c|c|c|c|c|c|c|c|}
\hline IV & 67452301 & efcdab89 & 98badcfe & 10325476 & & & & \\
\hline$M_{0}$ & $\begin{array}{l}\text { b02f512a } \\
\text { 633ed51 }\end{array}$ & $\begin{array}{l}\text { c7be044b } \\
\text { 3f40000 }\end{array}$ & $\begin{array}{l}13214 \mathrm{fe} 0 \\
8060 \mathrm{~b} 83 \mathrm{f}\end{array}$ & $\begin{array}{l}\text { c64ba7e7 } \\
\text { d2026306 }\end{array}$ & $\begin{array}{r}\text { 80c78f18 } \\
\text { df7ea316 }\end{array}$ & $\begin{array}{r}\text { fd09b7fa } \\
59 \mathrm{cfe} 3\end{array}$ & $\begin{array}{r}\text { 9b9da541 } \\
\text { fffdf }\end{array}$ & $\begin{array}{l}\text { fa069c37 } \\
\text { 804c0267 }\end{array}$ \\
\hline$H$ & 69bf3aa8 & 612a7041 & 125353f8 & $24072 \mathrm{fa} 0$ & & & & \\
\hline$M_{0}^{\prime}$ & $\begin{array}{l}\text { b02f512a } \\
\text { 633ed51 }\end{array}$ & $\begin{array}{l}\text { c7be044b } \\
3 f 40000\end{array}$ & $\begin{array}{l}\text { 13214fe0 } \\
8060 \mathrm{~b} 83 \mathrm{f}\end{array}$ & $\begin{array}{l}\text { c64ba7e7 } \\
\text { d202e306 }\end{array}$ & $\begin{array}{c}\text { 00c78f18 } \\
\text { df7ea316 }\end{array}$ & $\begin{array}{r}\text { fd09b7fa } \\
59 \mathrm{cfe} 3\end{array}$ & $\begin{array}{c}\text { 9b9da541 } \\
\text { 800fffdf }\end{array}$ & $\begin{array}{l}\text { fa069c37 } \\
\text { 804c0267 }\end{array}$ \\
\hline$H^{\prime}$ & e9bf3aa8 & a329f241 & $945355 f 8$ & a6072fa0 & & & & \\
\hline
\end{tabular}

Table 10. A Counterexample Satisfied Cnditions in Table 4 Ecept for $\mathrm{c}_{16,26}=1$

\begin{tabular}{|c|c|c|c|c|c|c|c|c|}
\hline IV & 67452301 & efcdab89 & 98badcfe & 10325476 & & & & \\
\hline$M_{0}$ & $\begin{array}{l}\text { fc552b76 } \\
\text { 633ed51 }\end{array}$ & $\begin{array}{r}58000108 \\
3 f 40000 \\
\end{array}$ & $\begin{array}{l}\text { ea1a196e } \\
\text { 8060b84f }\end{array}$ & $\begin{array}{l}\text { 131f05e1 } \\
12010307\end{array}$ & $\begin{array}{r}65 \text { ec } 44 \mathrm{~b} 7 \\
\text { efe } 02 \mathrm{fe}\end{array}$ & $\begin{array}{r}74 \mathrm{f} 3 \mathrm{a} 5 \mathrm{a} 7 \\
\mathrm{c0fdb} \\
\end{array}$ & $\begin{array}{r}\text { 9b9da541 } \\
\text { ff7fffef }\end{array}$ & $\begin{array}{l}\text { fa069c37 } \\
7 \mathrm{ffc} 018 \mathrm{e}\end{array}$ \\
\hline$H$ & 2e75bf44 & $7064 f 413$ & $230 c 5438$ & 5cd4be64 & & & & \\
\hline$M_{0}^{\prime}$ & $\begin{array}{l}\text { fc552b76 } \\
\text { 633ed51 }\end{array}$ & $\begin{array}{r}58000108 \\
3 f 40000\end{array}$ & $\begin{array}{l}\text { ea1a196e } \\
\text { 8060b84f }\end{array}$ & $\begin{array}{l}\text { 131f05e1 } \\
12018307\end{array}$ & $\begin{array}{r}\text { e5ec44b7 } \\
\text { efe } 02 f e\end{array}$ & $\begin{array}{r}74 \mathrm{f} 3 \mathrm{a} 5 \mathrm{a} 7 \\
\mathrm{c0fdb}\end{array}$ & $\begin{array}{r}\text { 9b9da541 } \\
\text { 7f7fffe }\end{array}$ & $\begin{array}{r}\text { fa069c37 } \\
\text { 7ffc018e }\end{array}$ \\
\hline$H^{\prime}$ & ae75bf44 & f2647413 & a50c5438 & ded4be64 & & & & \\
\hline
\end{tabular}

